\title{
Aspects of Political Wisdom in the Treatise Lao Tzu "Tao Te Ching"
}

Natalia P. Koptseva

Doctor of Philosophy, Professor, Siberian Federal University, Russia

Vladimir I. Kirko

Doctor of Physical and Mathematical Sciences, Professor, Siberian Federal University, Krasnoyarsk State Pedagogical University named after Victor Astafijev, Russia; decanka@mail.ru

\section{Doi:10.5901/mjss.2015.v6n5s2p119}

\section{Abstract}

"Tao Te Ching" by Lao Tzu has a worldwide cultural significance. There are different national traditions of studying of this treatise. The current importance "Tao Te Ching" is that the text contains the basic concepts of traditional Chinese culture. In Russia, the "Tao Te Ching" is analyzed about 200 years. This article discusses various aspects of dialectics wei 為 and wu wei 無為, contained in the treatise of Lao Tzu Tao Te Ching. Aspects of wu wei 無為 found in most of the chapters of the treatise 'Tao Te Ching'. In the Tao Te Ching Lao Tzu says about the special spontaneous activity 'make non- action.' Dialectics wei 為 and wu wei 無為 is the foundation of the political doctrine of the Far Eastern civilization, Chinese civilization. Philosopher and writer Leo Tolstoy had understanding the evolution of concepts of Tao and wu wei 無為. Leo Tolstoy was the first translator and publisher of Lao Tzu Tao Te Ching in Russian. Over 30 years he studied the Tao Te Ching, and came to the conclusion that the essence of Taoism is the essence of Christianity. Based on the ideas of Leo Tolstoy, we can build the interaction between Christianity and Taoism.

Keywords: political studies, Taoism, wisdom, Lao Tzu

\section{Introduction}

Current socio-economic, political and cultural processes that go to the People's Republic of China today, prove that the Chinese state - the biggest 'player' in the international arena. These processes have many causes, including the specific social and cultural practices, numbering several thousand years. In the writings of a number of European and Russian scientists had hypothesized about the integrity and autonomy of the Chinese society and Chinese culture, that social and cultural processes, including processes of social stratification, social and cultural norms, values, ideals consist entirely different way, societies than in the so-called 'western' type (Wright, 1969/1979; Torchinov E.A., 1998; Seidel A.K., 1969 and other). Despite the controversial nature of the civilization approach a number of contemporary scholars distinguish particular types of civilization - the Far Eastern civilization, which includes China, North and South Korea, Japan, Vietnam, Thailand, Singapore and others (Toynbee A.J., 1934-1969). There is some scientific convention related to the fact that the dominant key of this civilization, its reference points, the basic structures are of Chinese origin. We are talking about how social stratification, and the ideological concepts and ideals of the economy, traditional religions, Chinese Buddhism, linguistic specificity, literature, art, architecture, cultural norms and values, including the culture of everyday communication. On the other hand, Chinese society has a special social time, whose historical duration of today is not comparable with any other community. Originating at the same time ancient Egyptian civilization, the Chinese society is an example of the most stable and long-term development in the history of mankind. Largely this is due to socio-cultural and humanitarian practices that prove their worth for centuries and millennia of successful application. Stability of Chinese society has a specific cause in the unity and continuity of the Chinese culture, based on the unique writing and special relationship to the ancient cultural artifacts, especially the ancient philosophical and religious cultural texts.

\section{2. 'Tao Te Ching' - the Fundamental Text of Chinese Culture}

Core culture is a system of standards, ideals, values relating to economic and with it the spiritual activity of people. It is 
especially necessary to emphasize the bi-unity of ideals that are stored in the core of culture (Pivovarov, 2008). Relying on intellectual discovery of the German philosopher and sociologist Max Weber (primarily on his work 'The Protestant Ethic and the Spirit of Capitalism' (1950)) and philosopher Sergey Bulgakov (1931), is postulated a fundamental principle of dual unity and spiritual standards of economic activity in of a particular culture. Ideological ideals justify and give valuesemantic nature of the economic standards of people's lives, in turn, economic standards can exist only in reliance on the corresponding forms of spiritual and ideological (including religious) life. If bi-unity ideals of economic and spiritual life advocates a kind of cultural universals, the specific content of these ideals and their consolidation in most revered cultural texts reveals the specificities of each ethno-cultural groups, allows us to trace the socio-cultural dynamics of this social organism, identify historical moments breaking and disappearance of former cultural systems and folding fundamentally new standards, ideals, values. In this sense, this particular culture exists as long as there are live its basic ideals. Destruction of these ideals means the destruction of the culture itself. Create new ideals and standards marks the establishment of a new socio-cultural space, a new type of social organism.

The ancient Chinese text 'Tao Te Ching ' has all the hallmarks of the fundamental sacred text ( the 'core culture'), which for centuries preserved and translated the basic ideals of the Chinese society. This canonical text for one of the two ethnic cultural traditions of China - to Taoism. Although Confucius does not include the 'Tao Te Ching' composition of two basic canons of 'Four Books' and 'Pentateuch', and puts it in a third group of texts in 'Zi' ('Teachers'), but the value of the 'Tao Te Ching' for the China and global social and cultural space is difficult to overestimate. Despite the fact that there is a serious debate about the unity of the Taoist religious tradition, none of the participants in this debate does not express doubt that the ancient Taoist sacred text, their oldest 'revelation' - is the text 'Tao Te Ching'. So, M. Strikmen (1979), one of the most authoritative scholars of Taoism in the world, believes that 'Tao Te Ching' was created in the era of 'proto-Taoism ', while the tradition of Taoism era begins only with its institutional construction activity in the Taoist school of 'Heavenly mentors' (beginning in $1 \mathrm{AD}$ ). M. Strikmen believes that the special status of these revelations Taoist receive only after Taoism consciously distinguishes itself from other religious traditions, ancient and medieval China, and until then , Chinese scholars believe that it was created in the era of Zhang ('Hundred Warring States'). And the study of this text does not make one 'automatically' Taoist like reading works of Martin Luther does not do modern man Protestant. Given these arguments M. Strikmen and those who agree with him, it is necessary to emphasize the special value of 'Tao Te Ching' for the Chinese civilization as a whole. Should recognize the establishment, maintenance and translation the 'Tao Te Ching' major factor in the appearance and the unique dynamics of Chinese civilization (Girardot 1983).

In the XVIII century translation of the Tao Te Ching in Latin appeared in Britain, and since then attempts to translations in the west never ceased, their total number reaches about 250. Thus, the Tao Te Ching by the number of translations is second only to the Bible (Mair 1990). For this article, the publication "Lao Tzu's Tao-The-Ching. A Parallel Translation Collection" (1996) will be used, where gathered together four translations of the Tao Te Ching into English. Will also be used translation of Lao Tzu 'Tao Te Ching', which is made J. Legge and which was published in 1891.

Despite the huge number of translations, a large number of studies, the complexity of philosophical concepts that are contained in the Tao Te Ching, must be disclosed by comparing different concepts with each other.

The hypothesis of this study is that the concept of 'action'為 and 'non-action' 無為 have different meanings in different chapters of the Tao Te Ching. This meaning varies according to how the 'wei' ('action') and 'wu-wei' ('nonaction') refer to the concept of 'Tao'.

The purpose of the article - based on the analysis of some concepts 'Tao Te Ching' to reveal the peculiarities of the Chinese political outlook, which may manifest itself in the present (Ge Zhaoguang 1987).

\section{Political Aspects of Taoism}

In the history of philosophy impact basic ideas 'Tao Te Ching' by the political reality of the Chinese state is discussed in various aspects:

1) explicit and secret rivalry Taoism and Confucianism for a place at the court of the dominant ideology of a Chinese emperor;

2) the value of the Taoist school mentors Heavenly (tian shi) for the political history of ancient and medieval China;

3) the doctrine of the Taoist sage - teachers monarch.

Philosophy ideal ruler, which was established in Taoism contributed sacralization of state power. Moreover, Taoism comes from the fact that this Taoist - ideal ruler (not an alchemist and not a magician) (Seidel, 1979).

Political philosophy of Taoism has several important features: 
1) It is established and strengthened the concept of the ideal ruler, who had a real impact on the political practice of China throughout its history; This concept has a prototype in religious Taoism, where deified Lao Tzu teaches rulers (Mather 1979).

2) It is closely related to the ideas of Confucianism and Neo-Confucianism, Taoism and Confucianism confrontation is often overestimated;

3) It has been influenced by Legalism, which affects, in some terms of Taoism, such as Tao-fa (Torchinov, idem).

4) Political Taoism often acted as a basis for peasant political movements;

5) Community forms of Taoism have a serious impact on the Chinese people and ethnic psychology at the moment (Abaev 1983).

Thus, a more detailed understanding of political ideas in the Tao Te Ching, will clarify some important points of the Chinese political philosophy, including contemporary.

\section{Wei (Action) 為 and wu-wei (Non-Action) 無為 - the Main Principles of the Political Philosophy of Lao Tzu 'Tao Te Ching'}

Characters that make up the 'Tao Te Ching' - a special kind of signs, which are called 'logograms'. Unlike phonogram logogram - a sign indicating the real word, which is an abstract concept. Besides Chinese characters logograms assumed signs of ancient scripts such as Egyptian, Maya writing, the Aztecs, and the Persian cuneiform.

In modern philosophical tradition, there is a strong interest in the interpretation logograms basic text of Chinese civilization 'Tao Te Ching' (Ge Zhaoguang. 1987, Yoshioka Esitoeyu 1961, Pelliot and Wieger 1912, Kobzev 2006 and other).

'Action' 為 refers to the basic concepts of Chinese culture, as well as its variant - 'non-action'. 無為. Central to the philosophy of traditional Chinese concept of 'wu wei' 無為 emphasize numerous researchers (Graham 1978, Titarenko, Abaev 1994; Slingerland 2002 and other). The principle of 'non-action' is also a basic principle of state-building and perfect government: firstly, as the supreme act of the state and, secondly, as the ultimate goal and the highest ideal.

'Wei' 為 and 'wu wei' 無為 serve traditional ethical and anthropological concepts oppositional pair and repeatedly found in the various chapters of the treatise 'Tao Te Ching': Chapter 2, Chapter 3, Chapter 29, Chapter 37, Chapter 38, Chapter 43, Chapter 48, chapter 57, chapter 63, chapter 64.

'Wei' 為 and 'wu wei' 無為 together constitute the dialectical dyad concepts upon which the entire Chinese philosophy. 'Wei' has such varieties as 'syn' (action, behavior aimed at achieving justice) 'and' (a sense of duty, justice, integrity, honesty, and others) and 'shi' (the service associated with the benefits) (Kobzev 2006). However, in Taoism 'wei' 為 dialectically transformed into 'wu wei' 無為 in the principle of 'non-action' non-interference in the natural order of things, even if it seems that the interference corresponds to morality or law. Basis of dialectics 'wei 為 - wu wei' 無為 is set out in Chapter 2, 'Tao Te Ching':

"Therefore the Sage manages affairs without doing anything, and conveys his instructions without the use of speech" (J. Legge, trans.). trans.)

"Therefore the Sage manages affairs without ado, And spreads his teaching without talking" (Chang Wing tsit,

"Therefore the Sage keeps to the deed then consists in taking no action and practices the teaching that uses no word (Lau D.S. trans.)/

"Therefore The Sage dwells in nonactive affairs and practices the wordless teaching" (R. Henricks. trans.).

In different translations of this fragment of the second chapter the authors emphasize the lack of transfer activity, practice, goal setting. Near wu wei 無為 is always silence, the absence of words. Thus, wu wei 無為 in relation to the Sage - is self-integrity, does not need any amendments, adjustments or just interventions, Sage himself while always harmonious Nature

\section{Ideal the Ruler in the 'Tao Te Ching' Lao Tzu}

'Tao Te Ching' has the aspect of political treatise, because very often provides guidance rulers or discloses quality 'ideal ruler' who is able to be a 'conductor Tao' in managed their society. For an ideal ruler who is a follower of the Tao, and possibly with the help of state power to establish the principle of 'wu wei' 無為 in his state. This is evidenced by Chapter 3 of the treatise 'Tao Te Ching'. Interpreters are used in this chapter, words such as 'keep', 'force', 'purify', the meaning of which is the use of order, of force against those who exhibit inappropriate activity, bustling. Chapter Tao Te Ching 
explicitly states that 'low' activity, vanity, greed may be terminated in the state by applying the order of the ruler, with the help of state power. Paradoxically wu wei 無為 can be achieved through violence.

The ideal ruler in the 'Tao Te Ching' - this person will be able to embody the principle of 'wu wei' 無為 in all spheres of social life. Following the 'wu wei'無為 - is to follow the natural, so society - is part of a universal nature, and whoever it embodies the principle of 'wu wei' 無為, that corresponds to the true Tao. In Chapter 3, it is said like this:

"When there is this abstinence from

action, good order is universal". (J. Legge, trans.)

Theme the ideal ruler, which embodies the principle of public administration wu wei 無為, continues in chapter 10:

"In loving the people and ruling the state, cannot he proceed

without any (purpose of) action? In the opening and shutting of his

gates of heaven, cannot he do so as a female bird? While his

intelligence reaches in every direction, cannot he (appear to) be

without knowledge?" (J. Legge, trans.)

Translators use words such as 'purification from the dross', 'without resorting to action', 'taking no action', 'without using any knowledge'. Thus authentic wu wei 無為 opposite 'pollution dross' inauthentic knowledge and the vain action.

In Chapter 29, the ruler who in government uses force, violence, and is warned that such management will end the collapse of the state and the collapse of the activities of the ruler:

\section{"The kingdom is a spirit-like thing, and cannot be got by active doing. He who would so win it destroys it; he who would hold it in his grasp loses it"(J. Legge, trans.).}

It is interesting to compare the contributions of Chapter 29 of this fragment by J. Legge with translations of other famous interpreters.

"The empire is a sacred vessel and nothing should be done to it. Whoever does anything ruin it; whoever lays hold of it will lose it" (Lau D.S. trans.).

"The word is sacred vessel, which must not be tampered with or grabbed after. To tamper with it is to spoil it and the grasp it is to lose it" (Chang Wing tsit, trans.).

"The most sublime instrument in the world cannot be contrived. Those who contrive spoil it; those who cling lose it" (Waley Arthur trans.).

We see the paradox. Violence as a principle of government led to the collapse of the state. But wu-wei 無為 can be implemented by force, says the Tao Te Ching. Thus, the dialectic of public administration built on the principle of wuwei 無為, based on a dual meaning of 'state coercion ":

1) Conscious is reaching the 'top' of the ruler, the introduction of the principle of ' wu wei ' 無為 in everyday culture, than to stop the activity of "low Dao", the activity of greed and vanity;

2) State violence on a complex "natural' system of social interactions, the equilibrium of the system - the main value towards the state; this balance should not be destroyed because it could never recover. Such is the political philosophy of the Tao Te Ching .

\section{Harmony Political Principles and the Inner Nature of Events}

Social dialectics 'wei 為- wu wei 無為' fully complies with the dialectics of nature. Following the principle of 'wu wei 無為 ',we allow events to happen in accordance with their own nature. Where we think we saw 'weak' existence, actually starts a new movement, for which the future. What seems to be 'strong', 'powerful', already realized in time and space, so will soon disappear in his fait fact. This tells the famous chapter 43 'Tao Te Ching':

"The softest thing in the world dashes against and overcomes the hardest; that which has no (substantial) existence enters where there is no crevice. I know hereby what advantage belongs to doing nothing (with a purpose)" (J. Legge, trans.). 
The author of 'Tao Te Ching' understands that, despite the 'lightness' and 'naturalness' of his social philosophy, it is difficult for practical implementation. This provision is also emphasized in chapter 43:

"There are few in the world who attain to the teaching without words, and the advantage arising from non-action" (J. Legge, trans.).

\section{The Principle of ' Wu Wei' 無為 in Statecraft}

Chapter 48 is important for the disclosure of social dialectics wei 為- wu-wei 無為. It reveals the shift in the dialectics of knowledge dialectics of social choice. When the person personally, in practice understands the futility and even harmful changes on the existing natural order, it is able to grasp the meaning of the principle of 'non-action'. Acting contrary to the natural course of events, would never run the state for real, because not even see how it's possible to do, being absorbed 'inauthentic affairs'. Chapter 48 directly connects the knowledge of 'Tao' and the implementation of ' wei 為' in social activities:
"He who devotes himself to learning (seeks) from day to day to increase (his knowledge); he who devotes himself to the Tao (seeks) from day to day to diminish (his doing).
He diminishes it and again diminishes it, till he arrives at doing nothing (on purpose). Having arrived at this point of non-action, there is nothing which he does not do.
He who gets as his own all under heaven does so by giving himself no trouble (with that end). If one take trouble (with that end), he is not equal to getting as his own all under heaven" (J. Legge, trans.).

Following the principle of 'wu wei' in political activities, activities of state administration, allows the ruler to achieve the perfect quality of 'wisdom', which are aspects of 'mind' and 'justice.' Mystical relationship of the ruler and the people, which is postulated in Confucianism and Taoism, settle in the 'Tao Te Ching ' by ' wu wei .' Making the 'wu wei', the ruler becomes a wise and just, justice thus returns to the people as if they controlled 'by itself'. First person in chapter 57 the ideal ruler - sage argues that freed from passions and desires ruler naturally returns to his people better social status:

"I will do nothing (of purpose), and the

People will be transformed of themselves; I will be fond of keeping

Still, and the people will of themselves become correct. I will take

No trouble about it, and the people will of themselves become rich; I

Will manifest no ambition and the people will of themselves attain to

The primitive simplicity" (J. Legge, trans.).

At the level of one person wei becomes the principle Taoist specific activity, as indicated by Al Kobzev. He argues that Wu Wei suggests a natural and spontaneous activity in the form of 'non-action implementation' (wei wu wei), 'do inaction.' This is fully consistent with the essence of 'permanently inactive,' but the universal Tao and implemented in the same manner Dae-grace (Kobzev idem, 450).

Really wei allows to carry out 'great' affairs as contemplating Dao may find the source of all cases and carry out these great things where they are still small - from their natural source. Obstacles that arise along the way, overcome by 'De-Virtue.' Contemplating natural Tao, acting in accordance with it possible to carry out all the complicated things 'easy'. Such ethical justification for the principle of 'wu wei' can be found in Chapter 63, 'Tao Te Ching':

(It is the way of the Tao) to act without (thinking of) acting;

To conduct affairs without (feeling the) trouble of them; to taste

Without discerning any flavor; to consider what is small as great,

And a few as many; and to recompense injury with kindness (J. Legge, trans.).

\section{Unity of Moral and Social Action}

Unity of moral and social action, which takes place at the 'wise man' - the only thing that can lead to the goal. Where 
controlled processes are just beginning, it may seem that they are easy to destroy, alter. However, by doing so, people (including the ruler) will be daily losses and defeats. Losses can be avoided if the to understand the course of the Tao and to refrain from any actions which contradict it. It is inherent in the social behavior of "wise men". This topic is discussed in detail in Chapter 64:

Therefore the sage desires what (other men) do not desire, and does Not prize things difficult to get; he learns what (other men) do not Learn, and turns back to what the multitude of men have passed by. Thus he helps the natural development of all things, and does not dare To act (with an ulterior purpose of his own) (J. Legge, trans.).

Amplified the theme of unity genuine social and moral action in Chapter 74. Here, even without reference to the law of the Tao, the author of the treatise speaks of the universality of the principles of action. The man who takes up the rights judges, and even the executioner, thereby making it possible appeal court and retaliation and to himself. Copyright ancient treatise formulates universal 'Golden Rule of morality' in Chapter 74:

There is always One who presides over the infliction death. He who Would inflict death in the room of him who so presides over it may be Described as hewing wood instead of a great carpenter. Seldom is it That he who undertakes the hewing, instead of the great carpenter, Does not cut his own hands! (J. Legge, trans.).

\section{Impact "Wu Wei" on the Philosophy of Leo Tolstoy}

Leo Tolstoy is not only a world-renowned writer, he sought to create a new religious outlook. His spiritual pursuits were associated with Christianity, Hinduism, Buddhism, Taoism and Confucianism. In modern philosophy quite well studied attitude of Leo Tolstoy to the Russian Orthodox Church. His work is analyzed from the point of view of the influence of Buddhism. But research on the influence of Taoism philosophy of Leo Tolstoy have few work. Their number is not enough (Bodde 1950, Schiffman 1971, Kondrashova and Surovtceva 2009, Kim Ryoho 2006, Jurkov 2000, Liu Chao 2008).

In 1891 Leo Tolstoy called the names of Confucius, Mencius and Lao Tzu in the context of a significant impact on his outlook. Leo Tolstoy described the impact of Lao Tzu on his creativity using the word 'great.' (Kondrashova and Surovtceva id.). Leo Tolstoy first read the Tao Te Ching in 1871 in a French translation by Stanislav Julien. In 1884 Leo Tolstoy wrote fragments of 67 chapters of the Tao Te Ching. The archive of the writer kept notes, which he did next to these fragments. In 1884, March 11 Leo Tolstoy wrote in a letter to Vladimir Chertkov: 'I'm very busy Chinese wisdom. I would like to convey to you and all that moral benefits that I have made these books '(Tolstoy 2006). Leo Tolstoy is the first translator of the Tao Te Ching into Russian. For his translation he used French and German translations. Leo Tolstoy believed that the concept of 'Tao' is Russian analogue of the concept of 'Love'. 'Tao-Love' is a higher principle by which man achieves unity with the world. Translation of Leo Tolstoy was incomplete. However, he made great efforts to Japanese scientist D.P Koissi published his translation of the Tao Te Ching in the journal 'Problems of Philosophy and Psychology' in 1894.

In 1903, Leo Tolstoy published fragments of the Tao Te Ching, in his book 'Thoughts on wise people every day'l And these fragments he published in 1909 a few months before his death. In 1910 he published 64 sayings of Lao Tzu, who was short and carefully edited by Leo Tolstoy. For this book, he wrote a short article entitled 'On the essence of the teachings of Lao Tzu'. This book was a great success and has been reprinted several times in Russia. Leo Tolstoy has its own unique interpretation of the basic boat Taoism: Tao, wu wei, bu yang, tien, te shen zhen. Tao and wu wei have the greatest importance in the study of Taoism, which did Leo Tolstoy. The concept of 'Tao' and 'wu wei,' he expounds in his writings: 'The Book of the way and the truth, written Chinese sage Lao Tzu' (1884), 'Not-Doing' (1893), 'Thoughts on wise people every day. Collected by Leo Tolstoy '(1903),' Letter to the Chinese '(1906),' The Sayings of the Chinese sage Lao Tzu elected Leo Tolstoy '(1910).

Features interpretation, which makes Leo Tolstoy in relation to the terms 'Tao' and 'wu wei', is as follows:

1) in the 1884 edition, he translates the term 'Tao' as 'God'; first line 'Tao Te Ching' Leo Tolstoy translated as follows: 'The God who can be called, is not God eternal' (Tolstoy 1884);

2) in the article 'Not-Doing' (1893) 'Tao' - is 'the way, virtue, truth'; knowledge of the Tao can only be achieved through wu wei, non-action. Leo Tolstoy wrote: 'All people disasters according Lao Tzu is not so much what they did, how much of what they are doing, what not to do' (Tolstoy 1992, 4, 185-200); 
3) in the book 'Thoughts wise people every day' (1903) Tao - it's mind, wu wei - is 'humility' or even 'complete humility'; changed translation of the first lines of the Tao Te Ching: 'Mind that you can comprehend, is not perfect mind' (Tolstoy 1992, 6, 87);

4) in the 'Letter to the Chinese' (1906) Tao - this is the true path to freedom, activities in accordance with the basic law of human life; wu wei - is not doing another thing you do not want to do to you (Tolstoy 1992, 5, 291292, 295);

5) in the 1910 book 'Tao Te Ching' Leo Tolstoy compares the 'Tao Te Ching' with the Gospel, with the First Epistle of St. John, and argues that the Tao - Love is the path connection with Heaven and Heaven itself, and God himself; wu wei - is 'not doing what the body does not want to' (Tolstoy 1992, 7, 351).

Thus the philosophy of of Leo Tolstoy is a synthesis of Christianity philosophy and philosophy of Taoism. It defines Tao and wu wei by integrating the spirit of Christian theology and Taoism. Leo Tolstoy wrote: 'The essence of the teachings of Lao Tzu has the same as the essence of Christian doctrine' (Tolstoy 1992, 7, 351).

Leo Tolstoy's spiritual quest led him to the idea that God can not be a person. Leo Tolstoy experienced a profound spiritual crisis associated with this understanding of God in the 1870s. Exiting deep spiritual crisis was associated with the study of the philosophy of Taoism, Confucianism, Hinduism, and Buddhism. By studying these philosophies Leo Tolstoy overcomes its crisis. Lao Tzu ideas brought him spiritual peace. He was able to overcome the crisis and to continue their work. Leo Tolstoy believed that the idea of Lao Tzu are the most fundamental, he believed in Taoism philosophy, religion and ethics are fused together.

\section{Conclusion}

Political ideas of the 'Tao Te Ching' based on dialectics wei and wu wei. This dialectic is manifested in most of the chapters of the Tao Te Ching. Can be called the Tao Te Ching anthology of Chinese political philosophy. Here manifest principles of society as a complex system of social communications. It is important that the Taoist ideal is the ideal of the perfect ruler. Dialectics wei and wu wei revealed through such processes as "wei wu wei " (to do "non-action") by rejecting the verbal expression of the truth, by refusing to make a decision about life and death.

Political philosophy, expounded in the Tao Te Ching, is inseparable from the universal moral law. The great Russian writer and philosopher Leo Tolstoy overcame deep spiritual crisis by studying Lao Tzu "Tao Te Ching'. More than 30 years before his death he was constantly studying the ideas of Lao Tzu. His understanding of the Tao and wu wei had a definite evolution. In the last period of his life, Leo Tolstoy came to the creation of synthesis of Taoism and Christianity. He believed that Christianity and Taoism are the universal essence of God, Tao and Love is equivalents, equivalents are the Christian concept of 'humility' and the Taoist concept of 'wu wei".

Leo Tolstoy's concept is of great importance in modern Russian philosophy. This concept is the basis for further study of Taoism, Confucianism, Buddhism in Russia. Leo Tolstoy's ideas are authoritative for those thinkers who are looking for a synthesis of Western and Eastern philosophy, a single source of universal human culture.

\section{References}

Abaev, N.V. (1983). Chan-Buddhism and Culture of Psychic activities in medieval China. Novosibirsk: Nauka.

Bodde, D., Speshneff, G. (1950). Tolstoy and China. Princeton University Press.

Bulgakov S.N. (1931). Soul socialism. Novy Grad, 1, 49-58.

Girardot, N.J. (1983). "Let`s get Physical", the Way of Liturgical Taosism. History of Religions, 23 (2), 170.

Graham, A.C. (1978). Later Mohist Logic, Ethics and Science. Hong Kong; L., 1978, § 1.4.32.

Jurkov, S.E (2000). On the 'non-doing' and 'universal boredom of being.' Leo Tolstoy and Lao Tzu. In: The Spiritual Heritage of Leo Tolstoy and modernity. Editors V.B Remizov, L.D Gromova-Opulskaya and others. Tula: Publisher TSPU Leo Tolstoy, 18-31.

Kim, Ryoho. (2000). "Not-Doing" Leo Tolstoy and Lao-Tzu. Problems of the Far East, (6), 152-163.

Kobzev, A.I (2006). Articles in the encyclopedia Spiritual Culture of China. Moscow: Eastern Literature, RAS, (1) Philosophy.

Kobzev, A.I Wei. Spiritual Culture of China. Vol. 1. Philosophy. Moscow: Eastern Literature: RAS, 189.

Kondrashova, L.I, Surovtceva, M.E. (2009) Chinese Philosophy in Russia: Leo Tolstoy and Lao tszy.Pyatye Torchinov reading. Philosophy, religion and culture of the East. S.V.Pahomov editor. St. Petersburg, 485-492.

Lao Tzu`s Tao-The-Ching. (1996). A Parallel Translation Collection. Compiled by B.Boison. Boston. Gnomad Publishing, Massachusetts. Liu, Chao. (2008). The Spirit search of Tolstoy and Confucianism, Taoism and Mohizm. Journal Boading University, 1.

Mair, V. (1990). Tao Te Ching: The Classic Book of Integrity and the Way.

Mather, R.B. (1979). K'ou Ch 'ien and the Taoist Theocracy at the Northern Wei Court, 423-451. Facets of Taoism. New Haven and London.

Pelliot, P., Wieger, L. (1912). Le taoisme (review). Journal Asiatigue. 
Pivovarov, D.V. (2009). Problem of Synthesis of the Main Definitions of Culture. Journal of Siberian Federal University. Humanities \& Social Sciences, 2(1), 17-22.

Schiffman, A.I (1971). Leo Tolstoy and the East. USSR Academy of Sciences. Institute of Oriental Studies; Editor T.L Motyleva. Nauka. Home Edition Oriental Literature.

Seidel, A.K. (1979). Le Fils du Ciest et le Maitre Celeste: note a propos des "Registres". Transactions of the International Conference of Orientalists in Japan (24). Tokyo.

Slingerland, E. (2002). Effortless Action: Wu-wei as Conceptual Metaphor and Spiritual Ideal in Early China. New York: Oxford University Press.

Strickmann, M. (1979). On the Alchimy of Tao Hung-ching. Facets of Taosism. New Haven and London, 164-167.

Tao Te Ching by Lao-tzu. (1891). Translator. J. Legge. Sacred Books of the East, (39).

Titarenko, M., Abaev, N. (1994). Wei. Chinese philosophy. Encyclopedic Dictionary. Ed. Titarenko M. Moscow: Thought.

Tolstoy, Leo. (1992). Complete Works. Moscow: Publisher "Terra".

Tolstoy, Leo. (2006). Complete Works. Volume 85. Moscow: Publisher of the Russian State Library: 37

Torchinov, E.A. (1998). Taoism. The experience of historical and religious descriptions. St. Petersburg: publishing house "LAN".

Toynbee, A.J. A (1934-1961). Study of History, 12 vols.

Weber, M. (1950). The Protestant Ethic and the Spirit of Capitalism. New York: Charles Skribner`s sons / London: George Allen and Uniwin LTD.

Wright, A.E. (1969 / 1979). Historian Reflections on the Taoist Tradition. History of Religions, 9, 2- 3.

Yoshioka, Esitoeyu Tonko Hon 'Taihe ke' nitsuite (About Dunhuang text 'Taiping Jing'). (1961). Toebunka kenkyudze Kieu (Notes of the Institute of Far Eastern culture). 